\title{
Disease progression and antiretroviral therapy in newly seropositive HIV subjects in a tertiary care hospital in North India
}

\author{
Sanjim Chadha ${ }^{1}$, Preena Bhalla ${ }^{1}$, Arun Kumar Jha ${ }^{1}$, Hitender Gautam ${ }^{1}$, Sanjeev Saini ${ }^{1}$, S. Anuradha ${ }^{2}$, \\ Richa Dewan ${ }^{2}$
}

\author{
${ }^{1}$ Department of Microbiology, Maulana Azad Medical College and Associated Hospitals, New Delhi, India \\ ${ }^{2}$ Department of Medicine, Maulana Azad Medical College and Associated Hospitals, New Delhi, India
}

\begin{abstract}
Introduction: In developing countries the standard methods used to monitor HIV disease progression and therapy response are clinical assessment, CD4+ T lymphocyte count measurement, and plasma viral load (PVL) quantification. These tests require expensive equipment and skilled technicians, so monitoring HIV in resource-limited countries remains challenging as few laboratories can offer these tests free of cost.

Methodology: Newly diagnosed HIV seropositive subjects $(\mathrm{n}=130)$ were categorized into three study groups: CD4 counts $<200$ cells/ $\mu 1$ (group A, 43 subjects); 200-500 cells/ $\mu 1$ (group B, 44 subjects); and $>500$ cells/ $\mu 1$ (group C, 43 subjects). At recruitment, PVL estimation was performed for group A subjects only, who were then initiated on highly active antiretroviral therapy (HAART) and were followed up after six months for evaluation of response to HAART by measuring the CD4 counts and PVL. Groups B and C were followed up after six months to monitor disease progression by measuring only CD4 counts.

Results: Among group A subjects, a rise in the median CD4 counts after six months of HAART was observed. At baseline, PVL ranged from 2636 to $>750,000$ copies/ml with a median PVL at baseline of 165,000 copies $/ \mathrm{ml}$. At follow-up, 90\% of the study subjects had undetectable levels of viraemia. Among group B and C subjects, a fall in the CD4 counts at follow-up was observed.

Conclusions: CD4 count is a powerful tool to determine response to antiretroviral therapy (ART) and monitor disease progression in HIV/AIDS. PVL is important to assess response to ART, especially in immunovirologic discordant responses.
\end{abstract}

Key words: CD4+ T lymphocyte count (CD4 count); HIV; highly active antiretroviral therapy (HAART); plasma viral load (PVL)

J Infect Dev Ctries 2013; 7(2):110-115.

(Received 17 July 2012 - Accepted 19 November 2012)

Copyright (C) 2013 Chadha et al. This is an open-access article distributed under the Creative Commons Attribution License, which permits unrestricted use, distribution, and reproduction in any medium, provided the original work is properly cited.

\section{Introduction}

HIV/AIDS continues to exact an enormous toll throughout the world, in both human and economic terms, posing a serious impediment to the growth and economic stability of many developing countries [1]. Based on HIV sentinel surveillance from 2008 to 2009 , it is estimated that India has an adult prevalence of $0.31 \%$ with 239,000 people infected with HIV, of whom $39 \%$ were female and $3.5 \%$ children. It is estimated that about 172,000 people died of AIDSrelated causes in 2009 in India [2].

Infection with HIV-1 produces a prolonged, gradually progressive disease which leads to opportunistic infections and eventually death. The initial asymptomatic period may last ten or more years depending on the virulence of the viral strain and the immune response and genetic makeup of the patient. With time the functional capacity of the immune system is impaired and the clinical signs and symptoms of AIDS become apparent $[3,4,5]$.

Currently the standard methods used to monitor HIV infection are clinical assessment, flow cytometry based $\mathrm{CD} 4+\mathrm{T}$ lymphocyte count (CD4 counts) measurement, and molecular assays to quantify plasma viral load (PVL). Though clinical assessment remains the most feasible approach, it lacks sensitivity in determining disease stage, progression, and therapy response; therefore, it should be used in conjunction with laboratory measures [6,7].

The CD4 count is the only immunological marker that is routinely measured, but the kinetics of its modification is slow and varies much among patients. The CD4 count was identified as a key predictor of risk of AIDS-defining diseases almost 20 years ago but several issues concerning its use have now arisen. These include the difference between short and longterm prediction, the use of CD4 percentage compared 
with absolute counts, the impact of antiretroviral therapy (ART) on the predictive value of the CD4 count, the role relative to other markers such as viral load, the derivation of scores to predict AIDS diseases, and the use of CD4 count as a surrogate endpoint, among others. Moreover, CD4 count does not reflect activation of the immune system, particularly in cases of immunovirologic discordant responses. In spite of all this, it continues to be a mainstay of monitoring for both untreated and treated patients [8,9].

The value of HIV-RNA quantification (Plasma HIV-1 viral load) as a prognostic marker has long been established. An approximately inverse relationship to the CD4 count and survival time has been observed in around $80 \%$ of patients [10,11]. Higher HIV-RNA levels are associated with more rapid decline of CD4+ T-cells, assisting prediction of the rate of CD4 count decline and disease progression $[12,13]$. Treatment response has been strongly linked to the baseline HIV-RNA level. Monitoring viral load is critical to assessing the efficacy of ART [14].

It has been shown by many Indian and foreign studies that CD4 counts fall and viral loads rise after successful antiretroviral therapy, whereas CD4 counts fall progressively in patients without HAART as the disease advances [15-17]. However, in some groups of patients, viral load decreases without appropriate immunologic recovery after HAART. Conversely, other patients respond immunologically to HAART without an important suppression in viral load. These two scenarios are known as discordant responses [1821].

Our study aimed to analyze disease progression and therapy response in newly diagnosed HIV seropositive subjects in a tertiary care centre in North India.

\section{Methodology}

The study was performed in the Department of Microbiology, Maulana Azad Medical College, New Delhi, from September 2007 to March 2010. A total of 130 newly diagnosed adult HIV seropositive subjects were enrolled. The study group was comprised of 88 males and 42 females over the age of 18 years. Informed consent was obtained from each participant prior to enrollment. The subjects were registered with the ART clinic of the hospital, staged according to the WHO clinical staging [22], and were then referred for CD4 count testing.

At the time of recruitment, blood samples were collected for CD4 counts in K3 EDTA (liquid) Vacutainer tubes (Becton, Dickinson and Company,
Franklin, NJ, USA). All study subjects were categorized into three study groups as follows: CD4 counts fewer than 200 cells $/ \mu 1$ (group A, 43 subjects); 200 to 500 cells $/ \mu 1$ (group B, 44 subjects); and more than 500 cells/ $\mu 1$ (group C, 43 subjects). Blood sample for PVL estimation was obtained for group A subjects only, at recruitment.

CD4 counts were determined by the FACSCount system (Becton, Dickinson and Company, San Jose, CA, USA). Plasma viral load (PVL) was estimated using an Amplicor HIV-1 Monitor Test, version 1.5 (Roche Diagnostics, Branchburg, NJ, USA) by the standard procedure (Detection limit 400-7, 50,000 copies $/ \mathrm{ml}$ ).

Group A cases were initiated on HAART including two nucleoside reverse transcriptase inhibitors (NRTIs) plus one non-nucleoside reverse transcriptase inhibitor (NNRTI) per National AIDS Control Organization recommendations [22]. All subjects (40 subjects) with haemoglobin counts higher than $8 \mathrm{~g} / \mathrm{dl}$ were started on zidovudine, lamivudine and nevirapine. Subjects who were anemic at the time of recruitment (3 subjects) or those who developed severe anemia (2 subjects) during the course of the above-said regimen were given a combination regimen of stavudine, lamivudine and nevirapine. These cases were followed up after six months for evaluation of response to HAART by measuring the CD4 counts and PVL. Group B and C cases were followed up after a period of six months to monitor disease progression by measuring the CD4 counts only. Forty-two age- and sex-matched HIV-negative healthy controls were also included for comparing CD4 counts with HIV-positive individuals.

To detect whether there was a significant difference in the levels of CD4 counts between baselines and follow-up, the Wilcoxon signed rank test was applied. The adopted significance level for statistical inference was $5 \%$ ( $\mathrm{p}$ value $<0.05)$.

\section{Results}

The median age of the HIV-seropositive study subjects was 32.5 years (IQR 24.2- 40.8) with a male to female ratio of 2.1:1. The predominant age group in males and females was 26 to 30 years. The most common mode of acquiring infection was heterosexual contact $(85.38 \%)$ followed by intravenous drug abuse $(9.2 \%)$. The majority $(75 \%)$ of the study subjects were from urban areas. Thirty-one percent of the males and $42 \%$ of the females were illiterate. Three percent of the study subjects had a positive VDRL (venereal disease research laboratory) test for syphilis, $6.9 \%$ 
Table 1. Change in absolute CD counts of subjects reported during follow-up

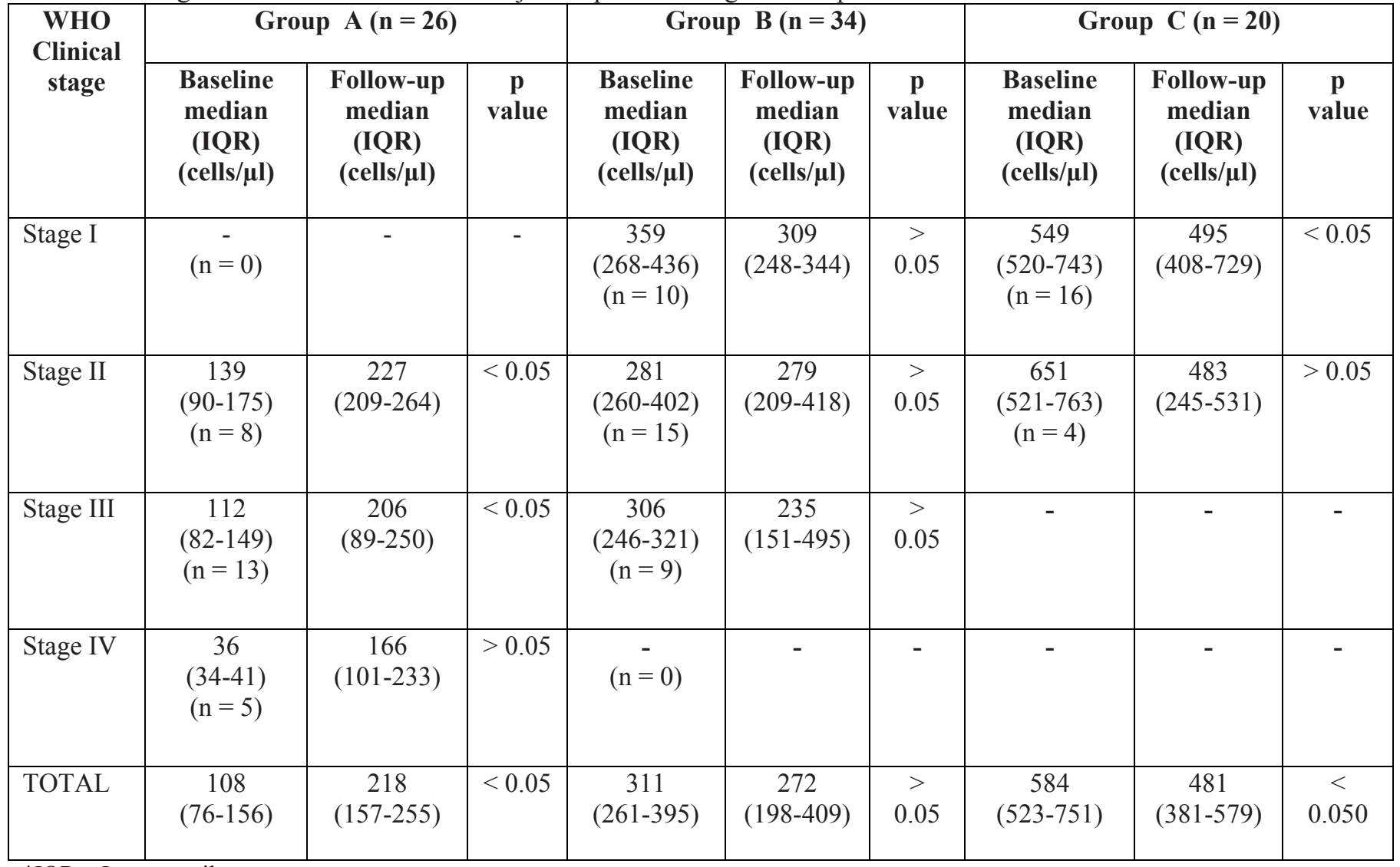

*IQR $=$ Inter quartile range

were positive for Hepatitis B surface antigen (HBsAg), and $2.3 \%$ were positive for anti-Hepatitis $\mathrm{C}$ virus (HCV) antibodies.

The median values of CD4 counts were significantly higher $(\mathrm{p}<0.5 ; 0.001)$ in the healthy control group as compared to HIV-positive study subjects (805 cells/ $\mu 1$; IQR $645-1063$ versus 279 Cells/ $\mu 1 ;$ IQR 154-482) at baseline.

Eighty of the 130 subjects recruited in our study reported for follow-up, and there were 15 fatal cases. Seven of these deaths were attributed to complications caused by AIDS and 4 to tuberculosis. Cause of death could not be ascertained in 4 cases because of lack of proper medical facilities in the rural villages where these patients lived; therefore, data on the cause of the terminal illness in these patients could not be collected. Thirty-five cases were lost to follow-up, which could be explained by fact that patients who were relatively symptom free did not feel the need to report to the ART clinic for follow-up after six months. Furthermore, some patients moved from their local residence to their native place to avoid stigma associated with the disease. Among group A subjects $(\mathrm{n}=43)$, twenty-six $(60.5 \%)$ subjects reported for follow-up and the adherence rate was greater than $95 \%$. Nine $(20.9 \%)$ subjects died within six months (four due to tuberculosis and five due to AIDS), and eight $(18.6 \%)$ were lost to follow-up. Among group B subjects $(n=44)$, thirty-four $(77.3 \%)$ subjects reported for follow-up, three subjects $(6.8 \%)$ died within six months (two due to AIDS and cause not known in one case), and seven subjects (15.9\%) were defaulters. Among group $C$ subjects $(n=43)$, twenty $(46.5 \%)$ reported for follow-up, three subjects (7\%) died within six months (cause unknown), and 20 subjects (46.5\%) were defaulters.

Table 1 shows the change in the CD4 counts of the subjects in the groups $\mathrm{A}, \mathrm{B}$ and $\mathrm{C}$ at follow-up after six months in relation to the WHO clinical stage of subjects at baseline. The number of subjects in the four different stages is also shown in the three groups.

In group $\mathrm{A}$, there was a statistically significant rise in the median CD4 counts after HAART (Table 1). Out of the 26 subjects who reported for follow-up, 
Table 2. Relation of CD 4 count with plasma viral load at baseline $(n=20)$

\begin{tabular}{|c|c|c|c|}
\hline $\begin{array}{c}\text { CD 4 COUNT } \\
\text { (cells/ } \boldsymbol{\mu l})\end{array}$ & \multicolumn{3}{|c|}{ Number (\%) of cases with PVL in copies/ml } \\
\hline & $\leq \mathbf{1 0 , 0 0 0}$ & $\mathbf{1 0 , 0 0 0 - 1 , 0 0 , 0 0 0}$ & $>\mathbf{1 , 0 0 , 0 0 0}$ \\
\hline$\leq 50$ & 0 & $1(5)$ & $3(5)$ \\
\hline $51-100$ & $1(5)$ & $2(10)$ & $1(5)$ \\
\hline $101-150$ & $1(5)$ & $2(10)$ & $5(25)$ \\
\hline $151-199$ & $1(5)$ & 0 & $3(15)$ \\
\hline TOTAL & $3(15)$ & $5(25)$ & $12(60)$ \\
\hline
\end{tabular}

PVL was performed only for 20 subjects due to limited resources. For these subjects at baseline, PVL ranged from 2,636 to more than $>750,000$ copies $/ \mathrm{ml}$ with a median PVL at baseline of 165,000 copies $/ \mathrm{ml}$. At baseline $75 \%$ of subjects with CD4 count $\leq 50$ had a viral load of greater than 100,000 copies/ $\mathrm{ml}$ (range 140,000- >750,000 copies/ml) (Table 2). At follow-up, the viraemia level was undetectable (i.e., viral load of less than 400 copies $/ \mathrm{ml}$ ) in $90 \%$ of the study subjects (Table 3). Three of the group A cases showed immunological failure according to National AIDS Control Organisation (NACO) guidelines. Out of these, two cases exhibited a fall in CD4 levels after six months of HAART (195 cells $/ \mu 1$ at baseline to 88 cells $/ \mu 1$ at follow-up and 110 cells $/ \mu 1$ at baseline to 94 cells/ $\mu$ l at follow up), while one case had CD4 levels persistently below 100 even after completing six months of HAART ( 5 cells $/ \mu 1$ at baseline to 40 cells $/ \mu 1$ at follow-up). Two of these cases with immunological failure showed undetectable viraemia at follow-up after six months of HAART, while one showed a viral load of 1,187 copies/ml (the case with CD4 counts of 195 cells $/ \mu 1$ at baseline fell to 88 cells/ $\mu 1$ at follow-up). One of our cases showed a viral load of 407 copies $/ \mathrm{ml}$ at follow up $(>750,000$ copies $/ \mathrm{ml}$ at baseline) but responded well immunologically (CD4 counts of 142 cells $/ \mu 1$ at baseline rising to 252 cells $/ \mu 1$ at follow-up). Therefore, immunovirologic discordant response was noted in three of our cases (15\%). Among group B, there was a fall in the level of CD4 counts at follow-up which was not statistically significant. Among group $\mathrm{C}$, a statistically significant fall in the CD4 counts was observed at follow-up (Table 1).

\section{Discussion}

Group A subjects in our study showed good clinical improvement after six months of HAART and none of the Group A subjects showed clinical failure. There was a statistically significant rise in the CD4 counts among subjects on HAART, indicating a good immunological response; these results are supported by the findings of another Indian study, in which the median CD4 cell count rose to 304 cells/ $\mu 1$ after three months of ART, and to 328 cells/ $\mu 1$ at six months [15]. In group B and C subjects, a fall in the CD4 counts was noted after six months as the disease advanced. In a study conducted by Mehendale et al. on Indian seroconverters, between the two periods of 91 to 360 days post seroconversion and 361 to 720 days post seroconversion, median CD4 counts dropped from $631 / \mu 1$ to $497 / \mu 1$. The annual decline in CD4 cell count was 120 cells per year among patients who were not on ART [16]. A study from France demonstrated a 240/ $\mu 1$ difference between baseline CD4 T-cell counts and counts taken after 3 years in the untreated group of HIV-1 infected patients with CD4 T-cell counts above $500 / \mu 1[17]$.

In our study, among group A patients, $90 \%$ of the study subjects responded well virologically; this observation is supported by results seen in another study in which $95 \%$ of the patients had undetectable viraemia after six months of ART [15].

Immunovirologic discordant response was noted in $15 \%$ of the cases in our study. Our findings corroborate those obtained from a study done in Karnataka, India, wherein $13.59 \%$ of the patients developed immunological failure over a period of 3.7 \pm 1.14 years of ART. These patients showed a "discordant response" as the HIV-1 RNA plasma level was below the limit of detection, but the CD4+ cell count response was blunted [23].

\section{Conclusion}

CD4 count is a powerful tool to determine response to HAART and also to monitor disease progression in newly diagnosed HIV-seropositive subjects. The drawback of this test is that it does not 
Table 3. Relation of CD 4 count with plasma viral load at follow-up $(\mathrm{n}=20)$ in Group A subjects

\begin{tabular}{|l|l|l|}
\hline PVL & $\begin{array}{l}\text { Undetectable } \\
\text { number (\%) }\end{array}$ & $\begin{array}{l}\text { Detectable } \\
\text { number (\%) }\end{array}$ \\
\hline$\geq \mathbf{1 0 0}$ & $16(80)$ & $1(5)$ \\
\hline$<\mathbf{1 0 0}$ & $2(10)$ & $1(5)$ \\
\hline
\end{tabular}

pick up non-responders to first-line ART with $100 \%$ certainty. Therefore, to prevent unnecessary switches to second-line ART, immunological failure should not be interpreted as failure to first-line ART without considering a viral load test. Unfortunately, in a country such as India where the disease burden is concentrated in rural areas, this may not be feasible as PVL estimation is not widely available. In 2008, NACO piloted a national strategy for the provision of free second-line ART in India; thus it is necessary to provide free-of-cost PVL estimation facilities in a large number of centers in India.

\section{Acknowledgements}

We are very grateful for the technical assistance offered by Mrs. Sujatha, technical supervisor in the HIV laboratory of our department.

\section{References}

1. Fauci AS (1999) The AIDS epidemic: considerations for the 21st century. N Engl J Med 341: 1046-1050.

2. NACO (2011) Department of AIDS Control, National AIDS Control Organization, Ministry of Health \& Family Welfare, Government of India, Annual Report 2010-11. Available: http://www.nacoonline.org/upload/REPORTS/NACO\%20An nual\%20Report\%202010-11.pdf. Accessed 24 October 2012.

3. Pascale JM, Isaacs MD, Contreras P, Gomez B, Lozano L ,Austin E, De Martin M C, Gregory RL, McLaughlin GL, Amador A (1997) Immunological markers of disease progression in patients infected with human immunodeficiency virus. Clin Diagn Lab Immunol 4: 474477.

4. Langford SE, Ananworanich J, Cooper DA (2007) Predictors of disease progression in HIV infection: a review AIDS Res Ther May 14: 11.5.

5. Pantaleo G and Fauci AS (1996) Immunopathogenesis of HIV infection. Annual Review of Microbiology 50: 825-854.

6. Balakrishnan P, Solomon S, Kumarasamy N, Mayer KH (2005) Low-cost monitoring of HIV infected individuals on highly active antiretroviral therapy (HAART) in developing countries. Indian J Med Res 121: 345-355.

7. Pattanapanyasat K (2012) Immune status monitoring of HIV/AIDS patients in resource-limited settings: a review with an emphasis on CD4+ T-lymphocyte determination. Asian Pac J Allergy Immunol Mar 30: 11-25.

8. WHO (2007) Laboratory Guidelines for enumerating CD4 T Lymphocytes in the context of HIV/AIDS.
Available:http://www.who.int/hiv/amds/LaboratoryGuideEnu meratingCD4TLymphocytes.pdf. Accessed 24 February 2012.

9. Jeganathan S, Bansal M, Smith DE, Gold J (2008) Comparison of different methodologies for CD4 estimation in a clinical setting. HIV Med 9: 192-195.

10. Lyles RH, Munoz A, Yamashita TE, Bazmi H, Detels R, Rinaldo CR, Margolick JB, Phair JP, Mellors JW (2000) Natural history of human immunodeficiency virus type 1 viremia after seroconversion and proximal to AIDS in a large cohort of homosexual men. J Infect Dis Mar 181: 872-880.

11. Thiebaut R, Pellegrin I, Chene G, Viallard JF, Fleury H, Moreau JF, Pellegrin JL, Blanco P (2005) Immunological markers after long-term treatment interruption in chronically HIV-1 infected patients with CD4 cell count above 400x10(6) cells/I. AIDS 19: 53-61.

12. Goujard C, Bonarek M, Meyer L, Bonnet F, Chaix ML, Deveau C, Sinet M, Galimand J, Delfraissy JF, Venet A, Rouzioux C, Morlat P (2006) CD4 cell count and HIV DNA level are independent predictors of disease progression after primary HIV type 1 infection in untreated patients. Clin Infect Dis 42: 709-715.

13. Touloumi G, Hatzakis A, Rosenberg PS, O'Brien TR, Goedert JJ (1998) Effects of age at seroconversion and baseline HIV RNA level on the loss of CD4+ cells among persons with hemophilia AIDS 12: 1691-1697.

14. WHO (2005) Guidelines for HIV diagnosis and monitoring of antiretroviral therapy. Available: http://www.searo.who.int/LinkFiles/Publications_HLM382Rev1.pdf. Accessed 1 January 2012.

15. Kumarasamy N, Vallabhaneni S, Flanigan TP, Balakrishnan P, Cecelia A, Carpenter CC, Solomon S, Mayer KH (2005) Rapid viral load suppression following generic highly active antiretroviral therapy in Southern Indian HIV-infected patients. AIDS 19: 625-627.

16. Mehendale SM, Bollinger RC, Kulkarni SS, Stallings RY, Brookmeyer RS, Kulkarni SV, Divekar AD, Gangakhedkar RR, Joshi SN, Risbud AR, Thakar MA,Mahajan BA, Kale VA, Ghate MV, Gadkari DA, Quinn TC, Paranjape RS (2002) Rapid disease progression in human immunodeficiency virus type 1-infected seroconverters in India. AIDS Res Hum Retroviruses 18: 1175-1179.

17. Piroth L, Binquet C, Buisson M, Kohli E, Duong M, Grappin M, Abrahamowicz M, Quantin C, Portier H, Chavanet P (2004) Clinical, immunological and virological evolution in patients with CD4 T-cell count above $500 / \mathrm{mm}_{3}$ : Is there a benefit to treat with highly active antiretroviral therapy (HAART)? Eur J Epidemiol 19: 597-604.

18. Flynn PM, Rudy BJ, Douglas SD, Lathey J, Spector SA, Martinez J, Silio M, Belzer M, Friedman L, D'Angelo L, McNamara J, Hodge J, Hughes MD, Lindsey JC; Pediatric AIDS Clinical Trial Group 381 Study Team (2004) Virologic and immunologic outcomes after 24 weeks in HIV type 1infected adolescents receiving highly active antiretroviral therapy. J Infect Dis 190: 271-279.

19. Sufka SA, Ferrari G, Gryszowka VE, Wrin T, Fiscus SA, Tomaras GD, Staats HF, Patel DD, Sempowski GD, Hellmann NS, Weinhold KJ, Hicks CB (2003) Prolonged CD4+ cell/virus load discordance during treatment with protease inhibitor-based highly active antiretroviral therapy: Immune response and viral control. J Infect Dis. 187: 10271037.

20. Dronda F, Moreno S, Moreno A, Casado JL, Pérez-Elías MJ, Antela A (2002) Long-term outcomes among antiretroviral- 
naive human immunodeficiency virus-infected patients with small increases in CD4+ cell counts after successful virologic suppression. Clin Infect Dis 35: 1005-1009.

21. D'Ettorre G, Forcina G, Andreotti M, Sarmati L, Palmisano L, Galluzzo CM, Nicastri E, Mastroianni CM, Vullo V, Vella S, Andreoni M (2002)Discordant response to antiretroviral therapy: HIV isolation, genotypic mutations, T-cell proliferation and cytokine production. AIDS 16: 1877-1885.

22. WHO-NACO, Ministry of Health \& Family Welfare, Government of India (2007) Anti-retroviral therapy guidelines for HIV-infected adults and adolescents including Postexposure Prophylaxis. Available from: http://www.ilo.org/wcmsp5/groups/public/---ed_protect/--protrav/---

ilo_aids/documents/legaldocument/wcms_117317.pdf. Accessed: 1 February 2012.

23. Prabhakar B, Banu A, Pavithra HB, Chandrashekhara P, Sasthri S (2011) Immunological failure despite virological suppression in HIV seropositive individuals on antiretroviral therapy. Indian J Sex Transm Dis 32: 94-98.

\section{Corresponding author}

Dr. Arun Kumar Jha

Senior Resident

Department of Microbiology

Maulana Azad Medical College

Bahadur Shah Zafar Marg

New Delhi, India

Pin Code: 110002

Fax: 91-11-23235574

Telephone: +919868489408

Email:dr_jhauc2k@yahoo.co.in

Conflict of interests: No conflict of interests is declared. 